\title{
Application and Research of Composite Insulators on the ACCC Conductor
}

\author{
Ge Changxin ${ }^{1}$, Liu Ren ${ }^{1}$, Zhao Chuanzong ${ }^{1}$, Wang $\mathrm{Yi}^{1}$, Liu Zhitong ${ }^{2}$, Sun \\ Fengwei $^{1}$, Zhu Bo ${ }^{1}$, Xie Xinnan ${ }^{1}$, Meng $\mathrm{Yu}^{1}$, Cui Xiaoyu ${ }^{1}$, Wang Qinghao ${ }^{1}$ \\ ${ }^{1}$ Fushun Power Supply Company, Liaoning Electric Power Company Limited, State Grid, China \\ ${ }^{2}$ Shenyang Power Supply Company, Liaoning Electric Power Company Limited, State Grid, China \\ fushunpowersupply@163.com
}

Keywords: ACCC, composite insulator, identification test

\begin{abstract}
This paper based on the 220kV ACCC wire part of Liao Yuan line composite insulator for insulating properties, mechanical properties and material performance testing, a comprehensive assessment of the effect of high temperature on the properties, define physical stability and reliability, composite insulator in determining long-term operation under high temperature wire provide guidance and recommendations for the application of composite insulator in ACCC on the conductor.
\end{abstract}

\section{Introduction}

At present, transmission lines in China widely used steel core aluminum stranded conductor (the ACSR wire), maximum use temperature of 100C. Composite insulator is insulating element universal application of transmission line, the curing temperature of mandrel is 170 to $180 \mathrm{C}$, the umbrella cover injection molding temperature 140 to $160 \mathrm{C}$, heat resistance in the operation stability, composite insulating materials can effectively curb the pollution flashover accident, reduce the insulator cleaning and zero value detection operation and maintenance management, to the decisive effect to enhance the safe operation of power transmission and transformation equipment up[1-3].

Carbon fiber composite core conductor (the ACCC wire) is high quality transmission conductor material model, compared with the conventional ACSR conductors, and has the advantages of light weight, high strength, low thermal expansion, high temperature resistant, low sag and large carrying capacity and many other advantages. Because there is no magnetic loss and thermal effect caused by the wire material, in the same transmission capacity, the operating temperature of ACCC is lower, can reduce transmission line loss of $6 \%$ or so, increase the carrying capacity of $29 \%$. At a temperature of $180 \mathrm{C}$ operation conditions, the load flow theory is two times of ACSR wires, the permissible temperature can be even more than $200 \mathrm{C}[4,5]$.

\section{Question analysis}

Once the temperature and duration exceeds a certain range, the epoxy resin mandrel within the migration occurs, silicon rubber material will deteriorate, the crimping strength of the mandrel and metal accessories connected region will decline, serious ,can cause the string dropping accident. Therefore, in actual operation, the safety performance of composite insulators under the condition of high temperature long what changes will occur? When the conductor temperature rise to $200 \mathrm{C}$, how to composite the temperature distribution of insulator ? Up to now, the property changes in the long-term and safe reliability of wire under the condition of high temperature composite insulator is also poorly understood, composite insulator in ACCC wire operation is still in the exploration of. Therefore, the test sample of composite insulators in operation, under various environment temperatures on the electrical properties, mechanical properties and material properties are able to meet the operating temperature of the ACCC wires required in-depth study, a comprehensive assessment of the physical stability of composite insulators in high temperature and long term reliability. 


\section{Performance characterization of composite insulator:}

1) Choose the subjects of composite insulator

In 2007 May, Fushun power supply company 220kV Liao Yuan line of original LGJ-400 type ACSR wire replacement for ACCC-713 type wire, carrying current from 840A to 1600A. This experiment used sample taken from the composite insulator Liao Yuan line operation, all for the pressing connection structure, running for 4 years, the ACSR wires running for 2 years, ACCC wires running for 2 years. Figure 1 is a sample of composite insulators.

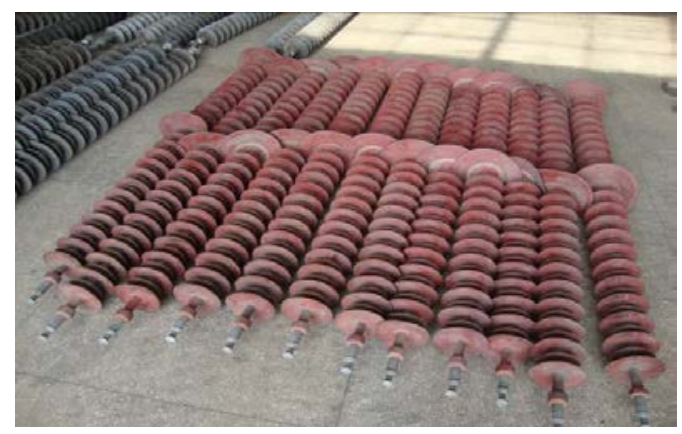

Figure 1 The sampling of composite insulator

2) Visual inspection

Carry out a visual inspection of the sample, in addition to surface fouling, different degrees of contamination phenomenon, no obvious deterioration phenomenon found. Inspection of the main contents is listed in the table 1.

Table 1 sample appearance inspection table

\begin{tabular}{|c|c|c|}
\hline Serial number & Check the contents & Conclusion \\
\hline 1 & Whether there is partial discharge traces of insulator surface & no \\
\hline 2 & $\begin{array}{r}\text { Whether Silicon rubber umbrella cover surface without erosion, tracking, } \\
\text { dendritic discharge or arc burn marks, etc. }\end{array}$ & no \\
\hline 3 & $\begin{array}{c}\text { Whether there is hardened, brittle, powder, crack } \\
\text { umbrella skirt is arranged between the degumming phenomenon }\end{array}$ & no \\
\hline 4 & $\begin{array}{r}\text { Whether the End fitting connecting parts are obvious slip, there are traces } \\
\text { of seal failure }\end{array}$ & no \\
\hline 5 & $\begin{array}{r}\text { Steel foot or steel cap whether there is corrosion, steel legs bent, the arc } \\
\text { erosion, lack of phenomena such as locking pin }\end{array}$ & no \\
\hline 6
\end{tabular}

3) Hydrophobic test

Using the spray method, for all specimen,taken the upper part (the grounding end), middle part, lower part(high end) surface hydrophobicity test, partial sample hydrophobic test is shown in Figure 2.
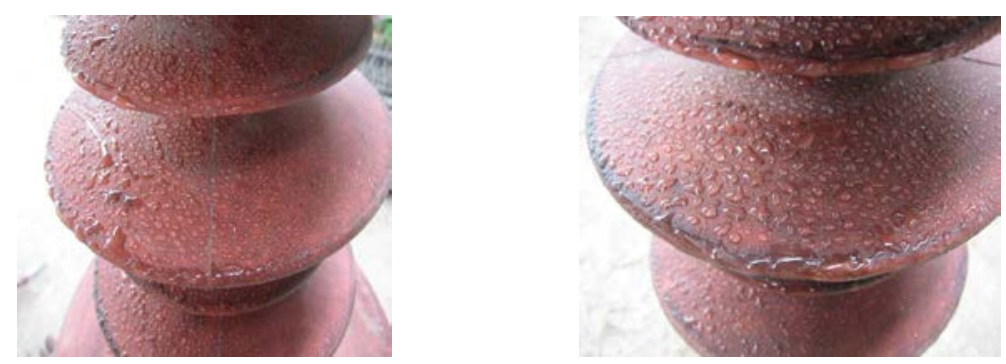

Figure 2 The sample hydrophobic test

Sample hydrophobic of HC4 and above, according to the DL/T 864-2004 standard for qualified, can continue to run. The measurement results are shown in table 2. 
Table 2 The hydrophobic test results

\begin{tabular}{|c|c|c|c|c|}
\hline \multirow{2}{*}{$\begin{array}{c}\text { Sample } \\
\text { number }\end{array}$} & \multicolumn{3}{|c|}{ Hydrophobic level } & Conclusion \\
\cline { 2 - 5 } & Upper part & Lower part & middle part & Qualified \\
\hline 1 & HC2 & HC3 & HC3 & Qualified \\
\hline 2 & HC2 & HC3 & HC3 & Qualified \\
\hline 3 & HC3 & HC3 & HC3 & Qualified \\
\hline 4 & HC2 & HC3 & HC3 & Qualified \\
\hline 5 & HC3 & HC4 & HC3 & Qualified \\
\hline 6 & HC2 & HC3 & HC3 & Qualified \\
\hline 7 & HC3 & HC4 & HC3 & Qualified \\
\hline 8 & HC3 & HC3 & HC3 & Qualified \\
\hline 9 & HC3 & HC4 & HC3 & Qualified \\
\hline
\end{tabular}

4) Electrical test current check

Take 3\#, 7\#, 1\# sample for electrical test. Frequency 1 min wet tolerance test

The sample water for 96h out, in the rain condition, the umbrella skirt surface is hydrophilic, then the pressure test, no obvious discharge phenomenon. With the test data and the results are presented in table 3 .

Table 3 frequency 1 min wet tolerance test report

\begin{tabular}{|c|c|c|c|c|c|}
\hline Sample number & $\begin{array}{c}\text { The specified } \\
\text { value } \\
(\mathrm{kV})\end{array}$ & $\begin{array}{c}\text { A correction } \\
\text { value } \\
(\mathrm{kV})\end{array}$ & $\begin{array}{c}\text { The applied } \\
\text { voltage } \\
(\mathrm{kV})\end{array}$ & $\begin{array}{c}\text { The tolerance } \\
\text { time } \\
\text { (min) }\end{array}$ & Results \\
\hline $3 \#$ & \multirow{3}{*}{395} & \multirow{3}{*}{395} & \multirow{3}{*}{398} & 1 & Tolerance \\
\hline 7\# & & & & 1 & Tolerance \\
\hline $1 \#$ & & & & 1 & Tolerance \\
\hline
\end{tabular}

The lightning impulse withstand voltage test

The sample water for $96 \mathrm{~h}$ out, in the rain condition ,the umbrella skirt surface is hydrophilic, lightning impulse withstand voltage test. The test results show that the lightning impulse level still meet the standard requirements. Detailed test data are listed in Table 4

Table 4 the lightning impulse withstand voltage test report

\begin{tabular}{|c|c|c|c|c|c|}
\hline $\begin{array}{l}\text { Sample } \\
\text { number }\end{array}$ & $\begin{array}{c}\text { Test waveform } \\
(\mu \mathrm{s})\end{array}$ & $\begin{array}{c}\text { A correction } \\
\text { value } \\
(\mathrm{kV})\end{array}$ & $\begin{array}{c}\text { The applied } \\
\text { voltage } \\
(\mathrm{kV})\end{array}$ & Tolerance times & Results \\
\hline $3 \#$ & \multirow{3}{*}{$1.21 / 50$} & \multirow{3}{*}{1006} & \multirow{3}{*}{$\begin{array}{c}1010 \sim \\
1022\end{array}$} & 15 & No flashover \\
\hline $7 \#$ & & & & 15 & No flashover \\
\hline $1 \#$ & & & & 15 & No flashover \\
\hline
\end{tabular}

Steep front impulse voltage test

Put the product into $\mathrm{NaCl}$, which concentration is $0.1 \%$,in solution boiling after $42 \mathrm{~h}$, sample retains extraction in a container until cooled to 50C , visual inspection samples of intact, steep wave impulse voltage test in the subsequent $48 \mathrm{~h}$. The test results show that the steep wave performance testing of products qualified. Steep front wave impulse voltage test results as shown in Table 5 .

Table 5 steep impulse voltage test report

\begin{tabular}{|c|c|c|c|c|}
\hline \multirow{2}{*}{ Sample number } & \multirow{2}{*}{$\begin{array}{c}\text { Wave steepness } \\
(\mathrm{kV} / \mu \mathrm{s})\end{array}$} & Positive & Negative & \multirow{2}{*}{ Results } \\
\cline { 3 - 5 } & \multirow{3}{*}{$1220 \sim 1430$} & 25 & 25 & No breakdown \\
\cline { 3 - 5 } & \multirow{2}{*}{122} & 25 & 25 & No breakdown \\
\cline { 3 - 5 } & & 25 & 25 & No breakdown \\
\hline
\end{tabular}

5) Seal test

Methods according to the provisions of ISO3452:1984 "nondestructive testing -- penetration test -- General principles", choose 3 supported trial product ,make staining test in metal accessories and insulating sheath interface permeability. The results show that the sample has good sealing. 
Detailed test data are listed in Table 6.

Table 6 metal accessories and insulating sheath interface of permeability test results

\begin{tabular}{|c|c|c|c|c|c|}
\hline \multirow{2}{*}{$\begin{array}{c}\text { Sample } \\
\text { number }\end{array}$} & $\begin{array}{c}\text { Penetration } \\
\text { time (min) }\end{array}$ & $\begin{array}{c}\text { Rechanical load } \\
(\mathrm{kN})\end{array}$ & $\begin{array}{c}\text { The tolerance time } \\
(\mathrm{min})\end{array}$ & $\begin{array}{c}\text { Surface } \\
\text { inspection }\end{array}$ & Conclusion \\
\hline 2 & 20 & 70 & 1 & No cracks & Qualified \\
\hline 6 & 20 & 70 & 1 & No cracks & Qualified \\
\hline 10 & 20 & 70 & 1 & No cracks & Qualified \\
\hline
\end{tabular}

Sampling the test Liao Yuan line of $220 \mathrm{kV}$ composite insulators appearance and no obvious deterioration, hydrophobic qualified; frequency 1 min wet withstand voltage test and the lightning impulse withstand voltage test, steep wave impulse voltage test meet the standard requirements; when the conductor temperature rise to $210 \mathrm{C}$, the environment temperature is $45 \mathrm{C}$, the highest temperature no more than 70C, in high voltage terminal portion of composite insulator. mechanical failure load values were higher than the rated value, the dispersion of small, and still has a large margin; below 70C, short-term mechanical performance of composite insulators are less affected, about 5\% 8\% at ambient temperature.

\section{Conclusion}

The results showed that, ACCC composite insulators put into operation dielectric strength and mechanical strength still meet the safety requirements, can continue to run. But considering the random test sample is less, the running time of only 2 years, and has not been fully tested high current operation conditions, partial sample hydrophobic has been reduced to HC4 level, in the next operation, also need to continue to track and detect the hydrophobic performance, to grasp the long-term variation of composite insulators and insulating properties and mechanical properties on the ACCC conductors running, accumulation of operating experience under high temperature conditions.

\section{References}

[1]Zhang Longcai,Jiang Xipei,Long Chuanyong.Status and Prospect of new composite materials composite core wire. China Electric Power Press, 2005

[2]Long Chuanyong. A Comparative Study of overhead transmission line conductors Capacity. Power Construction, 2007

[3]Zhao Zuoli, Wang Li, Jiang Zhenfu. Carbon fiber composite core aluminum wire used in the transformation of the grid lines in Liaoning. Power Construction, 2007

[4]Zhang Rui,Wu Guangya. Development and Prospect of key manufacturing technology of composite insulators. High Voltage Engineering, 2007

[5]Ding Jingling.Research Rod Composite Insulator Metal accessory connection zone mechanical properties. Porcelain arrester, 2006 